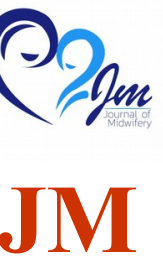

Volume 8 No. 1 (April 2020)

(C) The Author(s) 2020

\title{
PENERAPAN PROGRAM PERENCANAAN PERSALINAN DAN PENCEGAHAN KOMPLIKASI (P4K)
}

\author{
APPLICATION OF LABOR PLANNING PROGRAMS \\ AND PREVENTION OF COMPLICATIONS (P4K)
}

\author{
DARA HIMALAYA, DENI MARYANI \\ PRODI D3 KEBIDANAN FAKULTAS MIPA UNIVERSITAS BENGKULU \\ Email: dhimalaya@unib.ac.id
}

\begin{abstract}
ABSTRAK
Pendahuluan: Upaya pemerintah Indonesia untuk mendukung peningkatan pengetahuan dan perubahan prilaku ibu hamil yaitu dalam bentuk edukasi Program Perencanaan Persalinan dan Pencegahan Komplikasi (P4K) dengan menggunakan Stiker pada kelas ibu hamil. Kegiatan ini merupakan salah satu upaya keterlibatan masyarakat secara langsung dalam mengenal dan mencari pelayanan kesehatan yang berkualitas secara mandiri. pemasangan stiker pada setiap rumah yang ada ibu hamil, semua warga di desa tersebut mengetahui dan juga diharapkan dapat memberi bantu menyelamatkan ibu hamil dan ibu bersalin dengan persiapan taksiran persalinan, tempat persalinan yang sesuai, pendamping saat persalinan, transportasi yang akan digunakan dan calon pendonor darah. Prsiapan tersebut dapat mencegah kejadian komplikasi sehingga ibu mendapatkan pertolongan segera.Metode: Penelitian ini merupakan tinjauan literatur (literature review) dengan metode naratif yang mencoba menggali hasil penelitian terkait dengan penerapan Program Perencanaan Persalinan dan Pencegahan Komplikasi (P4K).Sumber pencarian data melalui database terkomputerisasi dari google cendekia (google sholar) dari tahun 2013 sampai tahun 2019 Kriteria pemilihan hasil penelitian dari jurnal nasional.Hasil: Jenis penelitian ini adalah analitik korelasional menggunakan rancangan croos sectionalmenunjukkan bahwa sebagian besarresponden mengoperasionalisasikan P4K dengan lengkap dan sebagian besar responden siap menghadapi komplikasi persalinan, terdapat hubungan antara operasionalisasi P4K dengan kesiapan ibu hamil menghadapi komplikasi persalinan.Kesimpulan: Peningkatan pengetahuan ibu hamil tentang cara kehamilan yang aman sampai dengan proses persalinan dan nifas merupakan salah satu faktor yang mampu mengoptimalkan upaya penurunan kejadian komplikasi dan kematian ibu, bayi dan balita.
\end{abstract}

Kata Kunci: Program, Persalinan, Komplikasi

\begin{abstract}
Introduction: The efforts of the Indonesian government to support the increase in knowledge and behavior changes in pregnant women in the form of education on the Birth Planning and
\end{abstract}


Prevention of Complications (P4K) Program by using Stickers in the class of pregnant women. This activity is an effort to directly involve the community in identifying and seeking quality health services independently. Installation of stickers on every house with pregnant women, all residents in the village know and are also expected to be able to help save pregnant women and women with childbirth preparation, appropriate delivery place, delivery attendants, delivery to be used and potential blood donors. Preparation can prevent complications so that mothers get immediate help. Method: This research is a literature review with a narrative method that tries to explore research results related to the implementation of the Birth Planning and Complications Prevention Program (P4K). Sources of data search through a computerized database from Google Scholar (Google Sholar) from 2013 to 2019 Criteria for selecting research results from national journals. Results: This type of research is a correlational analytic using a cross sectional design showing that most respondents fully operationalize P4K and most respondents are ready to face childbirth complications, there is a relationship between P4K operationalization and the readiness of pregnant women to face childbirth complications. Conclusion: Increasing the knowledge of pregnant women about safe pregnancy through childbirth and childbirth is one of the factors that can optimize efforts to reduce the incidence of complications and death of mothers, infants and toddlers.

\section{Keywords: Program, Childbirth, Complications}

\section{PENDAHULUAN}

Angka kematian ibu (AKI) di Indonesia tertinggi di Asia Tenggara dengan jumlah kematian ibu sebesar 228/100.000 Kelahiran Hidup (KH), jika dibandingkan AKI di Singapura sebesar 6/100.000 KH, Filipina $112 / 100.000 \mathrm{KH}$ dan di Brunei 22/100.000 KH. AKIdi Indonesia khususnya dalam mencapai target Sustainable Development Goals (SDGs) pada tahun 2015 yaitu AKI sebesar 102/100.000 KH dan Pada Tahun 2030, target AKI di Indonesia dapat dikurangi sehingga angka kematian ibu di bawah 70/100.000 KH.

Survei Demografi dan Kesehatan Indonesia (SDKI) Tahun 2012 menunjukkan peningkatan AKI yang signifikan yaitu menjadi 359 kematian ibu per 100.000 kelahiran hidup. AKI kembali menujukkan penurunan menjadi 305 kematian ibu per 100.000 KG berdasarkan hasil Survei Penduduk Antar Sensus (SUPAS,2015). Hal ini merupakan tantangan yang cukup berat bagi Pemerintah Indonesia.(KemenKes, 2017) KemenKes RI 2016, telah mengeluarkan terobosan dalam penurunan AKI dan AKB di Indonesiasalah satunya Program Perencanaan Persalinan dan Pencegahan Komplikasi(P4K).
Program tersebut menitikberatkan kepedulian dan peran keluarga dan masyarakat dalam melakukan upaya deteksi dini, menghindari risiko kesehatan pada ibu hamil, serta menyediakan akses dan pelayanan kegawatdaruratan obstetri dan neonatal dasar di tingkat puskesmas(PONED) dan pelayanan kegawatdaruratan obstetri dan neonatal komprehensif di Rumah Sakit (PONEK). P4K dalam implementasinyamerupakan salah satu unsur dari desa siaga. P4K mulai diperkenalkan oleh menteri kesehatan pada tahun 2007 (KemenKes, 2008).

Upaya penurunan AKI salah satunya adalah dengan pendekatan P4K. P4K merupakan program yang sudah lama ada sejak program Safe Motherhood dan program kesehatan ibu dan anakditujukan untuk menurunkan angka kematian ibu dan bayi. Penerapan program P4K melibatkan keluarga dan masyarakat bersama bidan berupaya dan membentuk kesepakatan kesanggupan masyarakat untuk membantu ibu hamil, ibu bersalin, bayi baru lahir dan masa nifas dalam bentuk merencanakan persalinan yang aman dan persiapan menghadapi komplikasi pada ibu hamil, termasuk perencanaan menggunakan metode Keluarga Berencana (KB) pasca persalinan dengan menggunakan 
stiker P4K sebagai media pencatatan sasaran dalam rangka meningkatkan cakupan dan kualitas pelayanan(DepKes RI, 2009).

Pelaksanaan P4K dicanangkan oleh Kementerian Kesehatan tahun 2007 dalam pelayanan kesehatan maternal. Fokus P4K adalah pemasangan stiker pada setiap rumah yang ada ibu hamil, adanya stiker di depat rumah semua warga di desa tersebut mengetahui dan juga diharapkan dapat memberi bantu menyelamatkan ibu hamill dan ibu bersalin dengan persiapan taksiran persalinan, tempat persalinan yang sesuai, pendamping saat persalinan, transportasi yang akan digunakan dan calon pendonor darah. Prsiapan tersebut dapat mencegah kejadian komplikasi sehingga ibu mendapatkan pertolongan segera (Prawiharjo, 2013)

Komplikasi persalinan, kehamilan dan nifas merupakan penyebab terbesar pada kematian ibu di Indonesia. Penyebab langsung AKI adslah perdarahan 28\%, Eklamsi $13 \%$, sepsis $10 \%$, aborsi $11 \%$, partus macet atau partus lama $9 \%$, kehamilan yang tidak diinginkan $7 \%$, lain-lain $22 \%$, sedangkan penyebab tidak langsung AKI adalah 3 Terlambat (Terlambat mengenal tanda bahaya dan mengambil keputusan, terlmbat mencapai fasilitas kesehatan, terlambat mendapat pertolongan di fasilitas kesehatan) (KemenKes, 2017).

Ibu hamil masih banyak yang kurang mengerti dan belum tahu tentang P4K dan belum berpatispasi apa yang tercantum dalam stiker P4K seperti tidak semua ibu hamil tidak mau menulis perencanaan persalinan yang tertera pada stiker $\mathrm{P} 4 \mathrm{~K}$ dengan alasan persalinan masih lama dan juga belum mempuyai perencanaan persalinan yang pasti. Banyak yang belum menempelkan stiker P4K di rumahnya, tetapi hanya diletakan di dalam buku KIA dan ditempel di lemari kamar dengan alasan malu dengan tetangga dan menganggap stiker itu tidak penting. Stiker P4K pertanda bahwa di rumah tersebut ada ibu hamil sehingga membuat ibu tersebut tidak terdata oleh bidan di desa sebagaii Pelaksana P4K (DepKes, 2009).

Masalah tersebut perlu di atasi, maka dibutuhkan upaya peningkatan pengetahuan dan perubahan prilaku ibu serta keluarga agar lebih menyadari bahwa pentingnya $\mathrm{P} 4 \mathrm{~K}$ pada masa kehamilan dan persalinan. Upaya untuk mendukung peningkatan pengetahuan dan perubuhan prilaku ibu hamil tersebut adalah kelas ibu hamil. Kelas ibu hamil adalah sarana belajar kelompok dalam bentuk tatap muka yang berisi pengayaan pengetahuan ibu beserta praktik mengenai perkembangan kehamilan, perawatan masa nifas, pentingnya ASI Eksklusif, kegiatan bejaran bersama, diskusi, dan tukar pengalaman mengenai Buku KIA dan pengisian Stiker P4K yang berisi program $\mathrm{P} 4 \mathrm{~K}$ secara menyeluruh (DepKes, 2009).

Tujuan P4K adalah Meningkatkan cakupan dan mutu pelayanan bagi ibu hamil dan bayi baru lahir melalui peningkatan peran aktif keluarga dan masyarakat dalam merencanakan persalinan yang aman dan persiapan menghadapi komplikasi dan tanda bahaya kebidanan bagi ibu sehingga melahirkan bayi yang sehat (DepKes, 2009).

Upaya P4K untuk mencegah komplikasi, sehingga untuk mewujudkan sistem tersebut maka dapat dilakukan dengan melibatkan berbagai lintas sektoral dengan unsur-unsur yang terdapat didalamnya. Unsur tersebut berisi tentang perencanaan persalinan yang meliputi rencana penolong persalinan, tempat persalinan, sarana transportasi, biaya persalinan, pendamping persalinan dan calon donor darah.Pertemuan ini dapat dilakukan di fasilitas kesehatan atau di rumah ibu hamil atau di posyandu (DepKes, 2009).

P4K pada ibu hamil dipengaruhi oleh beberapa faktor diantaranya pengetahuan, dukungan keluarga, situasi geografis dan budaya. Kurangnya pengetahuan baik ibu hamil atau masyarakat tentang kehamilan dan pencegahan komplikasi kehamilan mempengaruhi rendahnya cakupan $\mathrm{P} 4 \mathrm{~K}$. Anggapan bahwa kehamilan dan persalinan adalah sesuatu yang dialami sehingga tidak memerlukan pemeriksaan dengan perawatan akan menyebabkan ibu hamil termasuk dalam kelompok resiko tinggi (Pertiwi, 2013).

Pelaksanaan P4K di desa-desa tersebut 
perlu dipastikan agar mampu membantu keluarga dalam membuat perencanaan persalinan yang baik dan meningkatkan kesiapsiagaan keluarga dalam menghadapi tanda bahaya kehamilan, persalinan, dan nifas agar dapat mengambil tindakan yang tepat. Maka dari itu perlunya edukasi yang cukup agar keluarga dapat lebih siaga dalam menghadapi tanda bahaya kehamilan, persalinan, dan nifas (KemenKes, 2008).

\section{METODE PENELITIAN}

Penelitian ini merupakan tinjauan literatur (literature review) dengan metode naratif yang mencoba menggali hasil penelitian terkait dengan penerapan program perencanaan persalinan dan pencegahan komplikasi (P4K) Sumber pencarian data melalui database terkomputerisasi dari google cendekia (google sholar) dari tahun 2013 sampai dengan tahun 2019 tentang P4K berjumlah 12 jurnal penelitian. Hasil penelitian dipilih berdasarkan tema yang sesuai dengan judul artikel dan sudah dipublikasikan baik prosiding maupun jurnal. Kriteria pemilihan hasil penelitian jurnal nasional.

\section{HASIL PENELITIAN}

Keterlambatan ibu hamil mengenal tanda bahaya dan mengambil keputusan pelayanan kesehatan serta masalah 4 terlalu (terlalu muda melahirkan, terlalu sering melahirkan, terlalu rapat jarak melahirkan dan terlalu tua melahirkan), sampai dengan saat ini masih menjadi penyebab tidak langsung pada kematian ibu, bayi dan balita. Keadaan ini dilatarbelakangi oleh rendahnya pengetahuan ibu hamil dan keluarga dari itu perlunya edukasi yang cukup agar keluarga dapat lebih siaga dalam menghadapi tanda bahaya kehamilan, persalinan, dan nifas (KemenKes, 2008)

Upaya pemerintah Indonesia untuk mendukung peningkatan pengetahuan dan perubahan prilaku ibu hamil yaitu dalam bentuk edukasi $\mathrm{P} 4 \mathrm{~K}$ dengan menggunakan
Stiker pada kelas ibu hamil. Kegiatan ini merupakan salah satu upaya keterlibatan masyarakat secara langsung dalam mengenal dan mencari pelayanan kesehatan yang berkualitas secara mandiri. pemasangan stiker pada setiap rumah yang ada ibu hamil, semua warga di desa tersebut mengetahui dan juga diharapkan dapat memberi bantu menyelamatkan ibu hamil dan ibu bersalin dengan persiapan taksiran persalinan, tempat persalinan yang sesuai, pendamping saat persalinan, transportasi yang akan digunakan dan calon pendonor darah. Persiapan tersebut dapat mencegah kejadian komplikasi sehingga ibu mendapatkan pertolongan segera (DepKes, 2009).

Penelitian pertama merupakan penelitian yang dilakuakn oleh Ni Made W, 2016di Denpasar dengan desain penelitan dekriptif analitik dengan pendekatan cross sectional, data dikumpulkan dari responden dengan menggunakan kuesioner P4K. Sampel berjumlah 30 responden yang didapatkan dengan quota sampling. Hasil penelitian menunjukkan bahwa ibu hamil yang tidak menerapkan $\mathrm{P} 4 \mathrm{~K}$ cenderung mengalami komplikasi akan tetapi terdapat beberapa ibu hamil yang tidak menerapkan $\mathrm{p} 4 \mathrm{k}$ tidak mengalami komplikasi. dikarenakan pengalaman ibu saat hamil sebelumnya serta system imun ibu hamil yang terjaga dengan baik selama masa kehamilan dan terdapat hubungan antara penerapan program perencanaan persalinan dan pencegahan komplikasi oleh ibu hamil (P4K) dengan komplikasi kehamilan. Saran penelitian sebaiknya P4K diterapkan oleh ibu hamil agar dapat mengurangi tingkat terjadinya komplikasi kehamilan pada ibu hamil(Ni Made, dkk 2016)

Penelitian kedua penelitian dengan judul Hubungan operasionalisasi program perencanaan persalinan dan pencegahan komplikasi (P4K) dengan kesiapan menghadapi komplikasi persalinan pada ibu hamil trimester III dilakukan di Puskesmas Kota Denpasar Tahun 2018 oleh Ni Kadek Yuniasih. Jenis penelitian ini adalah analitik korelasional menggunakan rancangan croos 
sectional. Jumlah sampel sebanyak 56 sampel dengan menggunakan metode quota sampling. Hasil penelitian menunjukkan bahwa sebagian besar $(66,1 \%)$ responden mengoperasionalisasikan $\mathrm{P} 4 \mathrm{~K}$ dengan lengkap dan sebagian besar (64,3\%) responden siap menghadapi komplikasi persalinan. Terdapat hubungan yang signifikan antara operasionalisasi P4K dengan kesiapan ibu hamil menghadapi komplikasi persalinan dengan nilai $p=0,013$. Petugas kesehatan disarankan terus meningkatkan komunikasi informasi dan edukasi kepada ibu hamil trimester III dan melakukan kegiatan penyuluhan maupun promosi kesehatan kepada masyarakat(Ni Kadek Y, 2018).

Penelitian yang ketiga pelaksanaan di Purwoketo dengan judul Edukasi P4K pada kelompok ibu hamil desa Ledug sebagai upaya peningkatan pengetahuan kehamilan yang aman. Peserta kegiatan berjumlah $42 \mathrm{ibu}$ hamil dan kepala pemerintahan desa Ledug. Edukasi dilakukan dengan metodeceramah, penayangan video, diskusi dan praktek dengan media leaflet. Hasil:Terdapat peningkatan pengetahuan dan ketrampilan ibu hamil tentang cara kehamilan yang aman sampai proses persalinan dan nifas berdasarkan P4K. Kesimpulan:Peningkatan pengetahuan ibu hamil tentang cara kehamilan yang aman sampai dengan proses persalinan dan nifas merupakan salah satu faktor yang mampu mengoptimalkan upaya penurunan kejadian komplikasi dan kematian ibu, bayi dan balita. Dengan edukasi P4K ini, masyarakat dapat mengenal kesehatan secara mandiri sebagai upaya menurunkan keterlambatan mengenal komplikasi dan mencari pelayanan kesehatan yang tepat. (Willis D P,dkk 2019(3))

Penelitian ke empat berjudul Hubungan kelas antenatal mengenai program perencanaan persalinan dan pecegahan komplikasi dengan kesiapan persalinan ibu hamil trimester III di Denpasar Utara tahun 2019. Jenis penelitian kuantitatif dengan metode penelitian survei analitik. Desain penelitian ini menggunakan pendekatan waktu cross sectionaldilakukan pada tanggal
5 Mei s/d 2 Juni 2018. Besar sampel adalah 51 orang dengan teknik sampling non probability sampling berupa accidental sampling. Data yang dikumpulkan berupa data primer dengan pedoman wawancara terstruktur.Berdasarkan hasil penelitian dan pembahasan dapat disimpulkan bahwa terdapat hubungan antara kelas antenatal mengenai program perencanaan persalinan dan pencegahan komplikasi dengan kesiapan persalinan ibu hamil trimester III di Puskesmas III Denpasar Utara Tahun 2018. Ibu hamil disarankan untuk bisa mengikuti kegiatan kelas antenatal secara rutin, tenaga kesehatan dan kader diharapkan dapat mempertahankan pemberian informasi dan motivasi kepada ibu hamil mengenai pelaksanaan kelas antenatal dan memberikan edukasi kepada ibu hamil untuk menjaga kehamilannya serta mempersiapkan persalinannya secara baik (Ni Putu G, 2019).

Penelitian ke lima Pelaksanaan Program Perencanaan Persalinan Dan Pencegahan Komplikasi (P4K) Melalui Peran Keluarga Di Kabupaten Gowa Makasar pada tahun 2018. . Desain penelitian ini adalah kualitatif dengan rancangan deskriptif eksplanatif dengan menggunakan teknik purposive sampling dengan informan berjumlah 33 orang yang terdiri atas 6 orang ibu hamil, 4 orang suami, 5 orang kader posyandu, 3 orang bidan desa, 1 orang koordinator bidan puskesmas, 8 orang kepala lingkungan dan 6 orang kepala kelurahan. Kesimpulan dari hasil penelitian Peran keluarga dalam pelaksanaan program P4K di wilayah kerja Puskesmas Somba Opu Kabupaten Gowa telah dilaksanakan namun tidak secara maksimal. Ada beberapa indikator yang belum terpenuhi seperti kurang berpartisipasi dalam sosialisasi P4K, pemasangan stiker $\mathrm{P} 4 \mathrm{~K}$ dilakukan oleh ibu hamil atau kader posyandu, terdapat ibu hamil yang belum terdata, kunjungan rumah tidak. maksimal, keluarga tidak menyiapkan calon donor darah, ambulans desa, tabungan ibu bersalin (tabulin), dana sosial ibu bersalin (Dasolin), belum ada forum KIA, pertemuan bulanan hanya dalam bentuk posyandu. Saran penelitian diharapkan lebih 
meningkatkan partisipasi keluarga untuk ikut serta dalam pelaksanaan $\mathrm{P} 4 \mathrm{~K}$ seperti dalam bentuk penyuluhan dan sosialisasi serta meningkatkan kedisiplinannya dalam mengikuti anjuran petugas kesehatan dibantu dengan kader posyandu seperti dalam hal mempersiapkan calon pendonor darah, tabulin dan dasolin(Muh.Said M, dkk, 2019).

Hasil penelitian ke enam di Banten pada tahun 2016. Penelitian menggunakan metode kuantitatif dengan studi kohort dan menggunakan kuesioner dengan data primer. bahawa Karakteristik subjek penelitian yaitu kejadian komplikasi persalinan sebesar 12.5 \% dan keikutsertaan P4K $31.3 \%$ adalah ibu hamil yang tidak memanfaatkan $\mathrm{P} 4 \mathrm{~K}$ Terdapat hubungan yang signifikan antara pemanfaatan $\mathrm{P} 4 \mathrm{~K}$ pada ibu hamil dengan kejadian komplikasi persalinan.(Nintinjri $\mathrm{H}$, Nani Y, 2016)

\section{PEMBAHASAN}

Penelitian ke tujuh merupakan penelitian kualitatif yang dilaksanakan di Puskesmas Plupuh II Sragen pada bulan Mei 2017. Sumber data bidan coordinator, bidan desa, dan kader. Tehnik pengumpulan data dengan interview/indepth interview. Hasil Kegiatan pendataan ibu hamil dilakukan oleh bidan dan kader kesehatan. Bidan desa melakukan konseling tentang P4K pada ibu hamil. sebagai legalitas jika ibu hamil telah terdata dan diberi konseling P4K rumah ibu hamil ditempel dengan stiker P4K. Kegiatan pendataan ibu hamil dapat terlaksana dengan baik (100\%), notifikasi stiker P4K terlaksana dengan baik, penempelan stiker dilakukan oleh kader, ibu hamil, dan bidan desa. Pertolongan persalinan 100\% oleh tenaga kesehatan, tabulin belum terlaksana, ambulan desa menggunakan mobil masyarakat tetapi belum ada perjanijian secara formal kepada pemilik mobil, persiapan donor darah sudah ada tetapi belum ditest kesamaan golongan darahnya. Simpulan: Kegiatan pendataan ibu hamil dapat terlaksana dengan baik (100\%), pertolongan persalinan $100 \%$ oleh tenaga kesehatan, tabulin belum terlaksana, ambulan desa menggunakan mobil masyarakat, persiapan donor darah sudah ada tetapi belum ditest kesamaan golongan darahnya. Saran untuk Puskesmas agar meningkatkan lagi pelaksanaan program dengan diadakan kembali refreesing kembali bersama bidan dan kader untuk pelaksaan P4K, bagi bidan desa untuk meningkatkan kegiatan $\mathrm{P} 4 \mathrm{~K}$, dengan sweeping ke rumah ibu hamilagar hubungan dengan keluarga dan masyarakat di lingkungan ibu hamil lebih dekat untuk mengoptimalkan keterlibatan peran serta masyarakat dalam bidang kesehatan terutama pemantauan ibu hamil (Kamidah, Enny Y, 2017).

Penelitian ke delapan dengan judul Persepsi ibu hamil tentang program perencanaan persalinan dan pencegahan komplikasi (p4k) di kelurahan tanjung pinang kota jambi tahun 2014. Penelitian ini menggunakan metode penelitian deskriptif dengan rancangan cross sectional. Berdasarkan data hasil penelitian maka diperoleh kesimpulan sebagai berikut. Sebagian besar responden tidak ikut dalam Program Perencanaan Persalinan dan Pencegahan Komplikasi (P4K), sebagian responden memiliki pengetahuan yang baik $t$, sebagian responden memilki persepsi yang baik tentang Program Perencanaan Persalinan dan Pencegahan Komplikasi (P4K) terutama mengenai pengertian, tujuan dan manfaat Program Perencanaan Persalinan dan Pencegahan Komplikasi (P4K) namun ada sebagian kecil yang belum mengetahui tentang Program Perencanaan Persalinan dan Pencegahan Komplikasi (P4K) (Ruwayda, 2014).

Penelitian ke sembilan dengan judul Hambatan dalam implementasi program perencanaan persalinan dan mencegahan komplikasi (P4K) di Kabupaten Badung, 2019. Penelitian ini menggunakan metode deskriptif kualitatif dengan pendekatan fenomenologi dan data dianalisa secara tematik. Data dikumpulkan dengan cara focus group discussion (FGD). Informan ditentukan secara purposive dengan kriteria sasaran. 
Hasil penelitian menunjukkan pengetahuan, sikap, perilaku ibu hamil dan suami yang kurang mendukung pelaksanaan $\mathrm{P} 4 \mathrm{~K}$, sarana penunjang yang kurang seperti formulir, buku KIA dan biaya transportasi ke sasaran. Pengetahuan dan sikap bidan sangat baik tetapi perilakunya tidak mendukung pelaksanaan P4K. Pengetahuan dan sikap kader juga baik, tetapi perilakunya masih kurang dalam mendukung pelaksanaan $\mathrm{P} 4 \mathrm{~K}$. Faktor lain yang ditemukan adalah tata kelola puskesmas yang kurang mendukung serta mobilitas penduduk yang tinggi menyebabkan kesulitan dalam menemukan dan memantau ibu hamil. Hasil penelitian ini menunjukkan pentingnya meningkatkan penyebarluasan informasi, dukungan sarana, monitoring dan evaluasi, pengkajian terhadap penggunaan dana BOK dan peran berbagai sektor terkait (Putri M, dkk, 2019).

Penelitian ke sepuluh dilakukan oleh Warjidin A, Rosmadewi tahun 2013. Judul penelitian pengetahuan ibu hamil tentang program perencanaan persalinan dan pencegahan komplikasi ( $\mathrm{p} 4 \mathrm{k}$ ) pada antenatal care. Desain penelitian ini berjenis analitik dengan pendekatan crossectional. Populasi dalam penelitian ini adalah semua ibu hamil trimester III yang ada diwilayah Puskesmas Natar tahun 2013. Sampel dalam penelitian berjumlah 183 orang. Teknik pengambilan sampel menggunakan simple random sampling dengan cara diundi. Data yang digunakan data primer. Pengumpulan data menggunakan kuesioner. Berdasarkan hasil penelitian, mak kesimpulan bahwa pengetahuan ibu hamil tentang $\mathrm{P} 4 \mathrm{~K}$, lebih dari setengahnya memiliki pengetahuan baik yaitu sebanyak 54,1\% (99 responden), ibu hamil yang melakukan antenatal care, sebagian besar sesuai dengan standar yaitu sebanyak 92,9\% (170 responden). Pada analisis lebih lanjut diporoleh kesimpulan bahwa tidak ada hubungan antara pengetahuan ibu hamil tentang P4 dengan antenatal care di wilayah Puskesmas Natar dengan ( $p$ value $=0,787$ ). Dari kesimpulan diatas maka penulis menyarankan agar dipertahankan kinerja yang selama ini dilakukan sudah baik dan tetap menjadwalkan secara terus menerus disetiap pelayanan posyandu kegiatan penyegaran tentang program perencanaan persalinan dan pencegahan komplikasi. Pemeriksaan kehamilan minimal 4 kali selama hamil yang selama ini dilaksanakan untuk ditingkatkan menjadi kunjungan ibu hamil yang ideal yaitu 1 bulan sekali sebelum usia kehamilan 28 minggu, 2 minggu sekali pada usia kehamilan 28-36 minggu dan 1 minggu sekali pada usia kehamilan diatas 36 minggu. (Warjidin A, Rosmadewi, 2013)

Hasil Penelitian ke sebelas dengan judul Determinan faktor yang berhubungan dengan kinerja bidan dalam program perencanaan persalinan dan pencegahan komplikasi (p4k). Jenis penelitian yang digunakan adalah observasional analitik dengan pendekatan cross sectional. Penarikan sampel dengan proporsi cluster random sampling dengan besar sampel 43 orang. Analisa data menggunakan Chi Square.Hasil penelitian: hasil analisis data menunjukkan bahwa faktor yang berhubungan dengan kinerja bidan adalah masa kerja (nilai p 0,005), sedangkan faktor yang lain tidak ada hubungan, umur (nilai p 0,126), pendidikan (nilai p 0,497), pengetahuan (nilai p 0,266), inisiatif (nilai $\mathrm{p}$ 0,649) dan sikap (nilai p 0,716.). Kesimpulan terdapat hubungan masa kerja dengan kinerja bidan dalam pelaksanakan P4K di Kabupaten Sukoharjo (Sri Kustiyati, 2015)

Penelitian ke dua belas dilakukan oleh Yenni P, Eva S pada tahun 2017 di Bengkulu. Judul penelitian penyuluhan kelas ibu hamil tentang P4K.. Rancangan penelitian quasi experimental. Observasi dilakukan sebanyak 2 kali yaitu pre test, post test. ( pra eksperimental). Sampel dimabil secara total sampling. Hasil penelitian sebagian besar ibu hamil pada kelas ibu tidak mengetahui apa itu $\mathrm{P} 4 \mathrm{~K}$ dan manfaat stiker $\mathrm{P} 4 \mathrm{~K}$ sebelum dilakukan penyuluhan. Terjadi peningkatan pengetahuan ibu hamil pada kelas ibu tentang P4K dan manfaat stiker setelah dilakukan penyuluhan, serta ada hubungan penyuluhan pada kelas ibu terhadap pengetahuan dan partisipasi ibu dengan pemasangan stiker $\mathrm{P} 4 \mathrm{~K}$ 
sebelum dan sesudah penyuluhan (Yenni P, Eva S 2017).

\section{KESIMPULAN}

Berdasarkan analisis yang penulis lakukan terhadap dua belas penelitian yang relevan untuk dijadikan satu buah artikel ilmia ini dapat disimpulkan:

1. Ibu hamil yang tidak menerapkan $\mathrm{P} 4 \mathrm{~K}$ cenderung mengalami komplikasi

2. Peningkatan pengetahuan ibu hamil tentang cara kehamilan yang aman sampai dengan proses persalinan dan nifas merupakan salah satu faktor yang mampu mengoptimalkan upaya penurunan kejadian komplikasi dan kematian ibu, bayi dan balita.

3. Edukasi P4K masyarakat dapat mengenal kesehatan secara mandiri sebagai upaya menurunkan keterlambatan mengenal komplikasi dan mencari pelayanan kesehatan yang tepat.

4. Terdapat hubungan antara kelas antenatal mengenai program perencanaan persalinan dan pencegahan komplikasi dengan kesiapan persalinan ibu hamil trimester III

5. Pengetahuan, sikap dan perilaku ibu hamil, suami atau keluarga dalam pelaksanaan P4K kurang mendukung.

6. Pengetahuan, sikap bidan dan kader sangat positif dan mendukung pelaksanaan P4K, tetapi dalam pelaksanaannya belum menunjukkan perilaku yang mendukung pelaksanaan P4K.

7. Tata kelola atau manajemen puskesmas dan mobilitas penduduk yang tinggi, kurang mendukung pelaksanaan $\mathrm{P} 4 \mathrm{~K}$.

\section{SARAN}

Saran yang dapat diberikan pada:

1. Tenaga/tempat kesehatan:

(1) Bagi bidan terus meningkatkan komunikasi informasi dan edukasi kepada ibu hamil trimester III dan melakukan kegiatan penyuluhan maupun promosi kesehatan kepada masyarakat untuk menjaga kehamilannya serta mempersiapkan persalinannya secara baik.

(2) Bagi bidan desa untuk meningkatkan kegiatan $\mathrm{P} 4 \mathrm{~K}$, dengan sweeping ke rumah ibu hamilagar hubungan dengan keluarga dan masyarakat di lingkungan ibu hamil lebih dekat untuk mengoptimalkan keterlibatan peran serta masyarakat dalam bidang kesehatan terutama pemantauan ibu hamil.

(3) Diharapkan ada suatu metode pembinaan yang dilaksanakan untuk membuat persepsi positif bidan terhadap tugas-tugas yang diberikan kepadanya,

(4) Bagi puskesmas agar meningkatkan lagi pelaksanaan program dengan diadakan kembali refreesing kembali bersama bidan dan kader untuk pelaksaan P4K.

(5) Meningkatkan partisipasi keluarga untuk ikut serta dalam pelaksanaan P4K seperti dalam bentuk penyuluhan dan sosialisasi serta meningkatkan kedisiplinannya dalam mengikuti anjuran petugas kesehatan dibantu dengan kader posyandu seperti dalam hal mempersiapkan calon pendonor darah, tabulin dan dasolin.

(6) Tetap menjadwalkan secara terus menerus disetiap pelayanan posyandu kegiatan penyegaran tentang program perencanaan persalinan dan pencegahan komplikasi.

2. Ibu hamil/Masyarakat/keluarga

(1) Untuk bisa mengikuti kegiatan kelas antenatal secara rutin.

(2) Ibu Hamil selalu memeriksakan kehamilan secara rutin. 
3. Kader/toko masyarakat/ pemerintah daerah.

(1) Kader dapat mempertahankan pemberian informasi dan motivasi kepada ibu hamil mengenai pelaksanaan kelas antenatal dan memberikan edukasi kepada ibu hamil untuk menjaga kehamilannya serta mempersiapkan persalinannya secara baik.

(2) Diharapkan Dinas Kesehatan agar meningkatkan penyebarluasan informasi, penyediaan sarana secara berkesinambungan, pengkajian terhadap pemanfaatan dana BOK dan peningkatan monitoring dan evaluasi secara berjenjang.

\section{DAFTAR PUSTAKA}

Departemen Kesehatan RI. Pedoman Perencanaan Persalinan dan pencegahan komplikasi (P4K) dengan Stiker. Jakarta: Departemen Kesehatan RI. 2009.

Kamidah, Enny Yuliaswati. Program perencanaan persalinan dan pencegahan komplikasi (p4k) sebagai upaya menurunkan angka kematian ibu. STIKES Aisyiyah Surakarta Received: January 2018 | Revised: February 2018 | Accepted: February 2018. GASTER Vol. XVI No. 1 Februari 2018.

Kementerian Kesehatan. Data dan informasi profil kesehatan indonesia. Kementeri. Kesehat. RI (2017).

Kementerian Kesehatan. Pedoman Perencanaan Persalinan Dan Pencegahan Komplikasi (P4K) Dengan Stiker. (2008).

Muh.Said Mukharrim, Reza Aril Ahri, Yusriani. Pelaksanaan Program Perencanaan Persalinan Dan Pencegahan Komplikasi (P4K) Melalui Peran Keluarga Di Kabupaten Gowa. Jurnal Ilmiah Kesehatan, Vol. 18 No. 2 Tahun 2019. DOI : $10.33221 /$ jikes.v18i2.222

Pertiwi D. (2013). Hubungan Pengetahuan Dengan Sikap Ibu Hamil Tentang
Program Perencanaan Persalinan Dan Pencegahan Komplikasi (P4K) Sebagai Upaya Pencegahan Komplikasi Kehamilan Di Kelurahan KutambaruKabupaten Langkat Tahun 2013. Medan.

Ni Made Werdiyanthi, Mulyadi, Michael Karundeng. Hubungan Penerapan Program Perencanaan Persalinan dan Pencegahan Komplikasi Kehamilan Oleh Ibu Hamil dengan komplikasi kehamilan di puskesmas Doloduo kab. Bolaang Mongondow.E-Journal Keperawatan (EKP) Volome 5 Nomor 1 February 2017.

Ni Kadek Yuniasih. Hubungan operasionalisasi program perencanaan persalinan dan pencegahan komplikasi (p4k) dengan kesiapan menghadapi komplikasi persalinan pada ibu hamil trimester III. Studi Dilakukan di Puskesmas Kota Denpasar Tahun 2018.

Nintinjri Husnida, Nani Yuningsih. Hubungan antara keikutsertaan ibu hamil pada program perencanaan persalinan dan pencegahan komplikasi ( $\mathrm{p} 4 \mathrm{k})$ dengan kejadian komplikasi persalinan diwilayah kerja puskesmas warunggunung kabupaten lebak 2016. Jurnal Medikes, Volume 4, edisi I, April 2017

Ni Putu Gita Arneni, Ni Nyoman Sumiasih, Juliana Mauliku. Hubungan kelas antenatal mengenai program perencanaan persalinan dan pecegahan komplikasi dengan kesiapan persalinan ibu hamil trimester III. Studi dilakukan di Puskesmas III Denpasar Utara Tahun 2018. Jurnal Ilmiah Kebidanan: The Journal Of Midwifery; Vol. 7 No. 1 Tahun 2019

Prawiroharjo s. 2013. Ilmu Kebidanan Edisi Keempat Cetakan Ketiga. Penerbit PT Bina Pustaka Sarwono Prawirohardjo. Jakarta.

Putri Mariani, Putu Widarini, Alex Pangkahila.

Hambatan dalam implementasi program perencanaan persalinan dan mencegahan komplikasi (P4K) di Kabupaten Badung. 
Ruwayda. Persepsi ibu hamil tentang program perencanaan persalinan dan pencegahan komplikasi (p4k) di kelurahan tanjung pinang kota jambi tahun 2014. Jurnal Ilmiah Universitas Batanghari Jambi Vol.15 No.1 Tahun 2015.

Sri Kustiyati.Determinan faktor yang berhubungan dengan kinerja bidan dalam program perencanaan persalinan dan pencegahan komplikasi (p4k) 2015. GASTER Vol. XV No. 1 Februari 2017.

Warjidin Aliyanto, Rosmadewi.Pengetahuan ibu hamil tentang program perencanaan persalinan dan pencegahan komplikasi (p4k) pada antenatal caredi wilayah Puskesmas Natar tahun 2013.Jurnal Keperawatan, Volume X, No. 1, April 2014. ISSN 1907 - 0357.

Willis Dwi Pangesti, Inggar Ratna Kusuma.Edukasi p4k pada kelompok ibu hamil desa ledug sebagai upaya peningkatan pengetahuan kehamilan yang aman. LPPM-Universitas Muhammadiyah Purwokerto ISBN: 978602-6697-43-1.2019

Yenni Puspita, Eva Susanti. Penyuluhan Kelas Ibu Hamil Tentang P4K GASTER Vol. XV No. 1 Februari 2017 